\title{
CHARACTERIZATION OF AN EXTENDED GLUTAMATE RECEPTOR OF THE ON BIPOLAR NEURON IN THE VERTEBRATE RETINA ${ }^{1}$
}

\author{
MALCOLM M. SLAUGHTER ${ }^{2}$ AND ROBERT F. MILLER \\ Departments of Ophthalmology, Physiology, and Biophysics, Washington University School of Medicine, \\ St. Louis, Missouri 63110
}

Received April 11, 1984; Revised June 25, 1984; Accepted June 29, 1984

\begin{abstract}
The synaptic receptors of ON bipolar neurons are selectively activated by 2-amino-4-phosphonobutyrate, a glutamate analogue. This agent uniquely distinguishes these receptors from other types of excitatory amino acid receptors found in the retina. Various glutamate and aspartate analogues were used to assess the structureactivity characteristics of this receptor. The results suggest that it represents one class of glutamate receptor which can be distinguished by its preferential activation by acidic amino acid analogues that match the extended conformation of glutamate.
\end{abstract}

A decade ago, Murakami et al. $(1972,1975)$ demonstrated that aspartate and glutamate mimicked the actions of the photoreceptor neurotransmitter in the fish retina. This finding has been generalized to other vertebrate retinas and amplified upon in the fish. Neurotransmission at this junction is particularly interesting because single photoreceptors provide input to several classes of neurons, and evidence from our laboratory indicates that each class of second-order neuron possesses a distinct type of acidic amino acid receptor (Slaughter et al., 1983). This synaptic arrangement, in which one presynaptic neurotransmitter interacts with several postsynaptic receptor subtypes, is akin to that described for acetylcholine receptors in the pleural ganglion of Aplysia (Kehoe, 1967, 1969) and rabbit superior cervical sympathetic ganglion (Libet, 1979), and it offers an opportunity to compare the pharmacology of the receptor subtypes.

We have begun to explore differences in acidic amino acid receptors in the mudpuppy retina which, like other vertebrates, has photoreceptors that synapse on three classes of secondorder neurons: ON bipolars, OFF bipolars, and horizontal cells (Dowling and Werblin, 1969; Werblin and Dowling, 1969; Kaneko, 1970). The synaptic physiology of the photoreceptor to ON bipolar connection is unusual, and this is reflected in the synaptic pharmacology as well. A dark-released photoreceptor neurotransmitter depolarizes OFF bipolars and horizontal cells by opening channels, but apparently the same neurotransmitter hyperpolarizes the ON bipolars by closing ionic channels (Nelson, 1973; Toyoda, 1973; Werblin, 1979) Glutamate is hypothesized to be the cone transmitter onto all second-order neurons in the mudpuppy retina (Slaughter and Miller, 1983a). One

\footnotetext{
${ }^{1}$ We wish to thank Drs. G. Marshall, H. McLennan, P. KrogsgaardLarsen, and J. C. Watkins for generously donating excitatory amino acid analogues. This work was supported by National Eye Institute Grants RO1 EY 05085 and RO1 EY 03014.

${ }^{2}$ To whom correspondence should be sent, at his present address: Department of Biophysical Sciences, 118 Cary Hall, State University of New York at Buffalo, Buffalo, NY 14214.
}

glutamate analogue, 2-amino-4-phosphonobutyrate (APB), selectively activates only the $\mathrm{ON}$ bipolar receptors when applied at micromolar concentrations (Slaughter and Miller, 1981). Although excitatory amino acid receptors are present on most neurons in both the inner and outer retina (Slaughter and Miller, 1983a), APBs direct action is limited to the ON bipolar synapse. This selectivity of one glutamate analogue, in a retina that contains many types of glutamate-sensitive neurons, suggests that the $\mathrm{ON}$ bipolar synaptic receptor represents a distinct class of excitatory amino acid receptor.

Based on these observations we were interested in further characterizing the $\mathrm{ON}$ bipolar receptor by testing molecular conformations and substitutions of glutamate that produced a selective activation of these neurons. We were aided in this effort by the synaptic arrangement of the distal retina which permitted a comparison of the pharmacology of the ON bipolar with that of the OFF bipolar and the horizontal cell. This enabled us to find agents that discriminated between the three synaptic glutamate receptors found at one anatomical locus.

The molecular analysis used in this study relied on the threepoint binding of excitatory amino acids to their receptors which was established by the pioneering studies of Curtis and Watkins (1960). They demonstrated that the activity of acidic amino acids depended upon three groups: one amino and two carboxyl moieties. The subsequent development of both agonists and antagonists has relied on the alteration of the distance between these groups or on substitutions for these charged moieties. We used a similar approach to discern the three-dimensional arrangement of these binding sites at the $\mathrm{ON}$ bipolar receptor. We found that the uniqueness of this excitatory amino acid receptor could be explained by its preferential binding to ligands which had an intercarboxyl distance that exceeded $4 \AA$. These results reveal one type of excitatory amino acid receptor, identified by APB, which can be described as an "extended" glutamate receptor.

\section{Materials and Methods}

Experiments were performed in the superfused retina-cyccup preparation of the mudpuppy, Necturus maculosus, using standard electro- 
physiological techniques. The animals were decapitated and pithed before the eye, and the surrounding tissue was removed from the skull. The retina was exposed by excising the cornea, iris, lens, and vitreous. The rim of the eyecup was covered with a Kimwipe, leaving only the retina exposed. This preparation rested on a wad of Ringer's soaked cotton and was placed in a chamber inside a light-tight Faraday cage.

A pipette, placed at the rim of the eyecup, was used to introduce perfusate which formed a bath in the eyecup over the retina. The perfusate consisted of a control solution of amphibian Ringer's (111 mi $\mathrm{NaCl}, 2.5 \mathrm{mM} \mathrm{KCl}, 1.8 \mathrm{mM} \mathrm{CaCl}_{2}, 1 \mathrm{mM} \mathrm{MgCl} 2,10 \mathrm{~mm}$ dextrose, and $5 \mathrm{mM}$ HEPES buffered to $\mathrm{pH} 7.80$ ) or a Ringer's solution containing pharmacological agents. The different perfusion solutions were contained in a series of bottles which were connected through separate Teflon-lined valves and tubing to a mixing chamber. A short length of polyethylene tubing, that serves as the common exit from the mixing chamber, was fed into the perfusion pipette near the retina. The perfusates were bubbled with oxygen and the flow rate was maintained at approximately $2 \mathrm{ml} / \mathrm{min}$. This system permitted the addition of two or more solutions to the retina simultaneously, and the exchange time on switching solutions (due to dead space in the lines) was about 15 to $25 \mathrm{sec}$.

A dual-beam light bench projected focused images of a small spot $(200 \mu \mathrm{m})$, an annulus ( $400 \mu \mathrm{m}$ inner diameter; outer diameter $>$ retinal diameter), or a diffuse light onto the retina (irradiance $=5 \times 10^{-9} /$ $\mathrm{cm}^{2}$ ). Light responses were cone dominated under our experimental conditions. Microelectrodes ( 250 to 600 megohms) were filled with $3 \mathrm{M}$ potassium acetate and were advanced into the retina by a hydraulic microdrive using capacitative buzzing to facilitate cell penetration. Recordings were obtained using a Dagan model 8100 amplifier. Cellular conductance changes due to light stimuli or drug application were assessed by applying $0.1-\mathrm{nA}$ current pulses into the neuron through the recording electrode. Under control conditions, the voltage deflection due to this current injection was eliminated by the bridge balance, and then the voltage deflection seen during stimulation was used to evaluate changes in membrane conductance. More complete descriptions of the methodology have been presented previously (Miller and Dacheux, 1976; Slaughter and Miller, 1983a).

The D,L-2-amino-1-phosphonobutyrate and the D,L-2-amino-3-phosphonopropionate were obtained from Calbiochem. Dr. J. C. Watkins kindly provided samples of $\mathrm{D}, \mathrm{L}-2$-amino-5-phosphonovalerate, cis-2,3piperidine dicarboxylic acid, and the $\mathrm{D}$ and $\mathrm{L}$ isomers of 2-amino-4phosphonobutyrate (these compounds are now commercially available from Cambridge Research Biochemicals). Dr. H. McLennan generously supplied a sample of cis-1,3-amino-dicarboxylcyclopentane (ADCP), and Dr. G. Marshall kindly donated 4-amino-4 phosphonobutyrate. All other compounds were purchased from Sigma Chemical Co.

Ibotenate, a glutamate analogue that was used in this study, can apparently be converted to muscimol, a GABA analogue. This reaction can occur spontaneously or due to biological decarboxylation. When we used this compound we periodically assessed its effects on inner retinal neurons, where GABA has a very potent inhibitory action. We did not observe any inhibitory effects, suggesting that ibotenate degradation was minor in the course of our experiments.

\section{Results}

The photoreceptor neurotransmitter, which is released maximally in the dark, combines with the synaptic receptors of the ON bipolar, causing a hyperpolarization and a closing of ionic channels (Nelson, 1973; Kaneko and Shimazaki, 1975; Dacheux and Miller, 1976). APB has a similar effect on both membrane potential and conductance. This is illustrated in Figure 1 in which we compare the voltage and resistance changes produced by $\mathrm{APB}$ with those produced in dark by the photoreceptor transmitter. In the upper trace of Figure 1 a bridge-balanced negative current pulse was injected into an $\mathrm{ON}$ bipolar cell during the light stimulus, a period of relatively little photoreceptor input. The application of APB held the cell hyperpolarized during the light stimulus and increased the cell's input resistance as seen by the negative voltage deflection during the current pulse. This is similar to the conductance decrease produced by the photoreceptor transmitter as it hyperpolarizes the ON bipolar in the dark (Fig. 1, lower trace). Both negative and positive current pulses produced larger voltage deflections

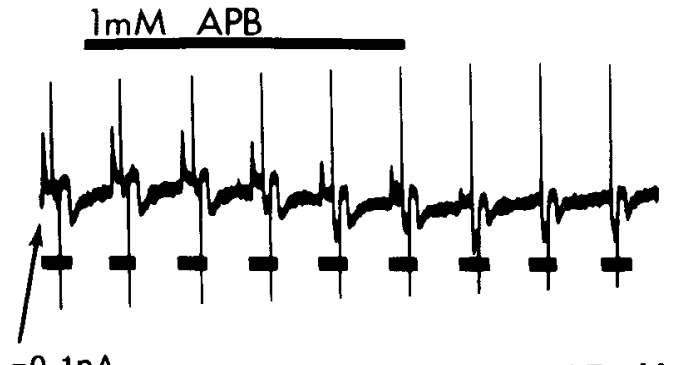

$-0.1 n A$

$15 \mathrm{mV}$

$20 \mathrm{sec}$

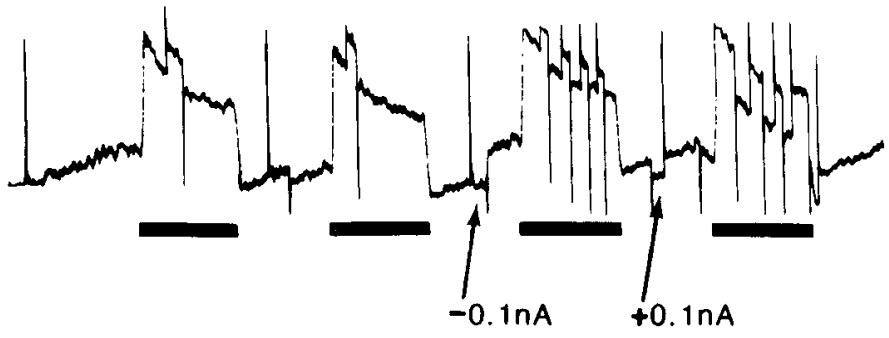

$20 \mathrm{mV}$

$5 \mathrm{sec}$

Figure 1. APB and the photoreceptor neurotransmitter produce similar conductance changes in ON bipolar cells. In the top trace, a $-0.1-n A$ current pulse is injected into an $\mathrm{ON}$ bipolar cell during the sustained portion of the light response, when relatively little photoreceptor transmitter is being released. The amplifier bridge is balanced so that this current produces only a slight voltage deflection. During the application of APB, the light response is suppressed and the negative current produces a larger negative voltage deflection, indicating an increase in the input resistance of the cell. In another ON bipolar, shown in the bottom trace, both negative and positive current pulses were applied. At the first arrow, a $0.1-\mathrm{nA}$ negative current pulse produces a negative deflection in the dark, but a positive deflection during the light response indicating that the photoreceptor transmitter also increases the neuron's input resistance in the dark. At the second arrow, a positive current pulse also indicated that the cell's input resistance was greater in the dark than in the light. The duration of drug application is indicated by the bar above the voltage trace and the timing of diffuse light stimuli is denoted by the bars below the traces.

in dark versus light. These observations not only show the similarity of action of APB and the endogenous transmitter, but they also lead to the conclusion that APB acts at synaptic sites on the ON bipolar since it eliminates the light response while it increases the cell's input resistance. If APB was acting nonsynaptically, the increase in input resistance would enhance, not suppress, the light response.

After establishing this synaptic site of action, we assessed the stereospecificity of this receptor by using the enantiomers of two selective glutamate agonists, APB and serine- $o$-phosphate. As shown at the top of Figure 2, $10 \mu \mathrm{M}$ L-APB mimicked the photoreceptor transmitter. The $D$ form also appeared to act as an agonist, although it was far less potent. We have found that serine-o-phosphate, which is similar in structure to APB, is also selective for the ON bipolar receptor. L-Serine-o-phosphate at $100 \mu \mathrm{M}$ was a potent agonist at the $\mathrm{ON}$ bipolar synapse, whereas a 50 -fold higher concentration of the $D$ isomer had little effect (Fig. 2, bottom). Although less potent that APB, serine-o-phosphate also demonstrates the L-sterospecificity of this synaptic receptor.

Early experiments indicating that aspartate and glutamate could mimic the action of the photorcecptor transmitter led to more recent efforts to discern which of these amino acids is the 
Figure 2. The stereospecificity of the $\mathrm{ON}$ bipolar synaptic receptor using two glutamate analogues that selectively activate these receptors. The $\mathrm{L}$ forms of APB and serine-o-phosphate are much more effective agonists than the $D$ forms of the square pulses indicate small spot stimuli while the downward pulses indicate annular stimuli. The arrows mark annular stimuli superimposed on a constant small spot stimulation, which evokes a surround response. Complete recovery of the light responses took another $2 \mathrm{~min}$ in the top three traces. same molecules. Diffuse light stimuli were used in the upper three traces; in the lower trace the upward

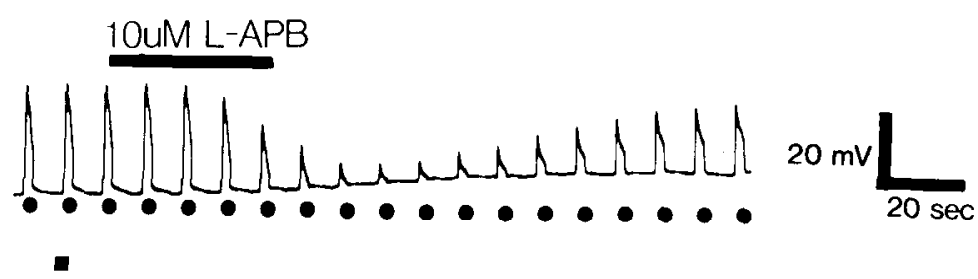

100uM D-APB

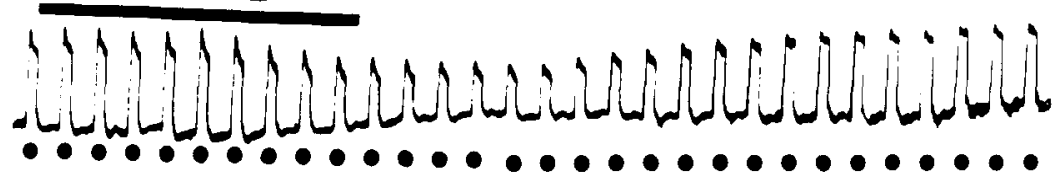

100UM L-OP SERINE

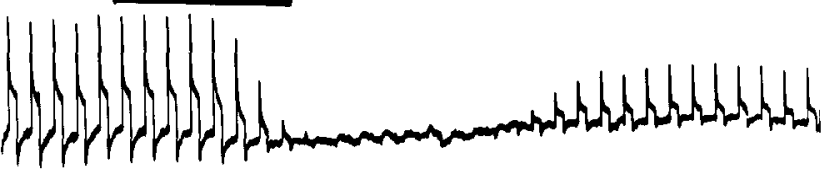

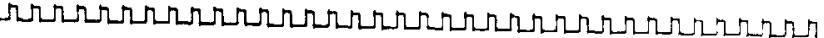

$5 \mathrm{mM}$ D-OP SERINE
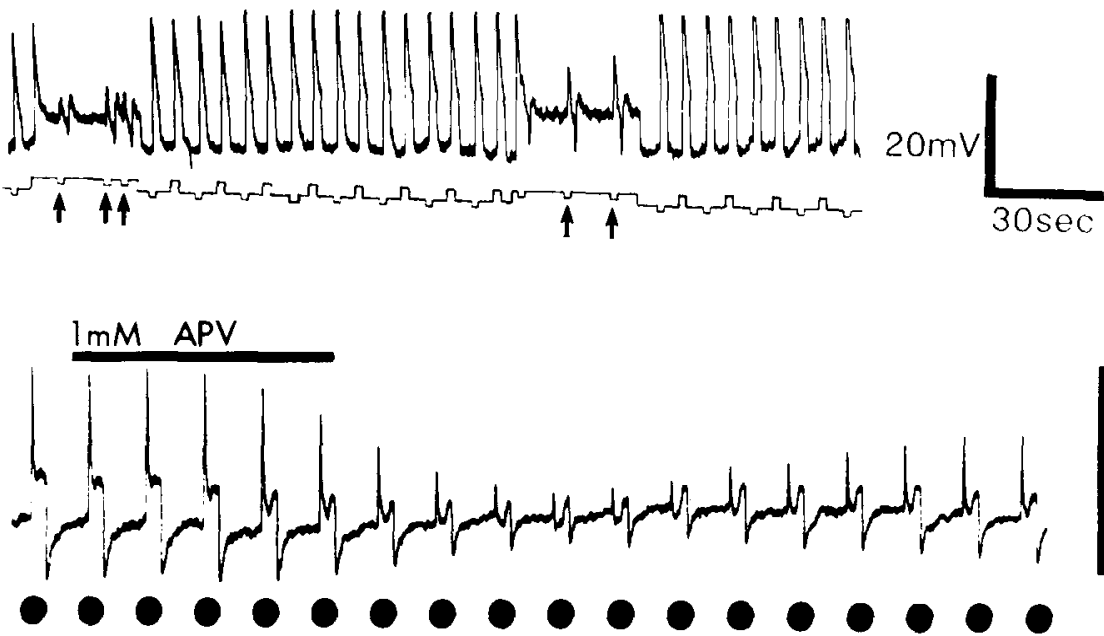

Figure 3. Comparison of the ability of three excitatory amino acid analogues to mimic the action of the. photoreceptor neurotransmitter. APB (middle) a glutamate analogue, is much more potent than 2amino-5-phosphonovalerate $(A P V)$, whereas 2amino-3-phosphonopropionate $(A P P)$, an aspartate analogue, is ineffective. The large solid circles symbolize diffuse light, the small solid circles symbolize small spot, and the open circles symbolize annular stimuli.

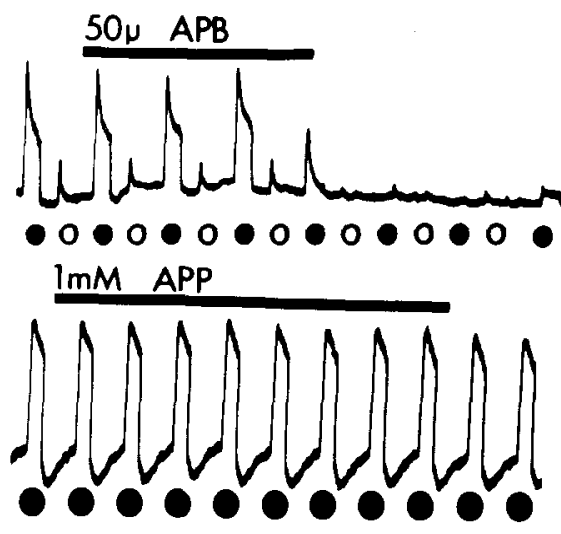

$20 \mathrm{mM}$ 
more likely transmitter. We have attempted to make this discrimination at the $\mathrm{ON}$ bipolar receptor. In one approach, we compared the potency of phosphonic acid homologues: (1) the aspartate analogue, 2-amino-3-phosphonopropionate, (2) the glutamate analogue, 2-amino-4-phosphonobutyrate, and (3) a compound that is one carbon longer than glutamate, 2-amino5 -phosphonovalerate. Representative results are shown in Figure 3 and illustrate that the glutamate analogue is the most potent. The longer chain molecule has a weaker agonist action, whereas the aspartate analogue is ineffective at $1 \mathrm{~mm}$ concentrations.

Although there are no potent and selective glutamate antagonists available, there are several useful aspartate agonists and antagonists. They presumably identify aspartate receptors, and their ineffectiveness at an excitatory amino acid receptor site suggests that glutamate may be the transmitter. Using this approach to differentiate aspartate from glutamate receptors, we tested the effects of $N$-methyl aspartate, an aspartate agonist, and D- $\alpha$-aminoadipate, an aspartate antagonist (Watkins and Evans, 1981). As shown in Figure 4, even high doses of these two agents did not appear to alter the synaptic responses of the ON bipolar cells. In fish horizontal cells, $\alpha$-methylglutamate has been shown to have an antagonist action similar to that of $\alpha$-aminoadipate (Ariel et al., 1982). This agent did not block the light responses of the $\mathrm{ON}$ bipolar (Fig. 4, bottom). These negative results argue against a role for aspartate receptors in cone neurotransmission at this synapse.

The foregoing findings indicated that the $\mathrm{ON}$ bipolar receptor could be classified as glutamate preferring. However, we have found that the OFF bipolar and the horizontal cells also possess glutamate-preferring receptors (Slaughter and Miller, 1983a, c). Since APB, a glutamate analogue, acts only at the $\mathrm{ON}$ bipolar receptor, these neurons must contain a distinct type of glutamate receptor and certain properties of APB must make it a very suitable ligand for this receptor. The phosphonic acid moiety in APB is more acidic than the corresponding carboxylic

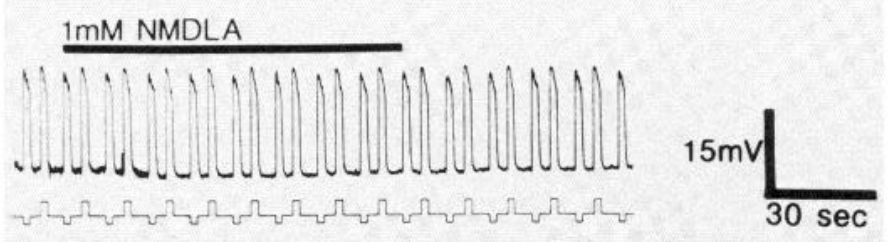

2mM D-alpha AMINO ADIPATE

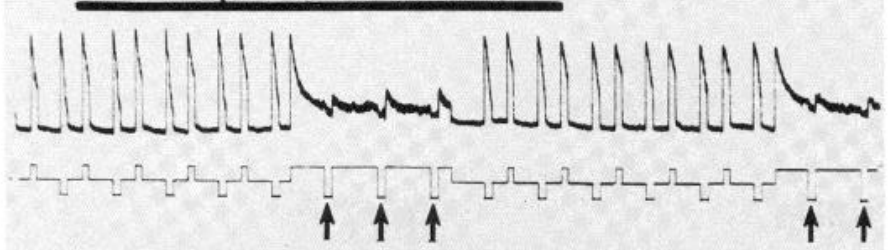

$5 \mathrm{mM}$ alpha METHYL GLUTAMATE

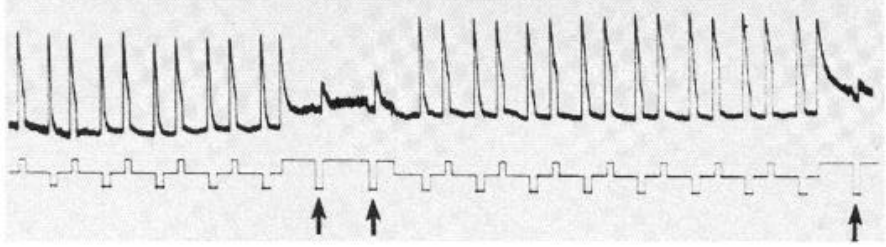

Figure 4. The ineffectiveness at the $\mathrm{ON}$ bipolar synapse of three agents which have been reported to act as aspartate receptors. Upward square pulses indicate small spot stimuli, small downward pulses indicate annular stimuli, and the long downward pulses marked with arrows indicate annular stimuli in the presence of a constant small spot stimulation. acid of glutamate. The importance of this factor in the selectivity of APB was evaluated by using glutamate and APB analogues with sulfonic acid substitutions, thus providing a terminal group similar in acidity to APB. This substitution was tested in several ways. Initially, we examined the thiol ( $\mathrm{SH})$ substituted analogues of aspartate and glutamate. Neither analogue appeared active, as seen at the left of Figure 5. When the sulfonic acid analogues were tested, cysteic acid, the aspartate analogue, had little effect whereas homocysteate had a more potent action, again demonstrating the preference of this receptor for glutamate-like ligands. However, homocysteate was significantly less potent than APB and, perhaps more importantly, it was less selective since it depolarized several other classes of glutamate-sensitive neurons in both the inner and outer retina. We also compared the potency of serine- $O$-phosphate and serine- $O$-sulfate. As already mentioned, L-serine- $O$ phosphate is similar in structure to APB and acts as a selective agonist at the $\mathrm{ON}$ bipolar synapse at a concentration of 100 $\mu \mathrm{M}$. In contrast, L-serine- $o$-sulfate did not show a noticeable agonist effect at this receptor at a concentration of $1 \mathrm{~mm}$ (Fig. $6)$. These results indicate that the acidity of the terminal group does not appear to account for the potency and selectivity of APB.

Another characteristic of the phosphonic acid moiety of APB is that its bond length is slightly longer than a carboxyl moiety and it contains two hydroxyl groups that are ionized at physiological $\mathrm{pH}$ levels. These molecular differences suggested that APB could easily assume an extended conformation, whereas the folded conformation of this molecule might be energetically less favorable than the corresponding, folded glutamate molecule. As early as 1960, Curtis and Watkins demonstrated that the action of excitatory amino acids depended upon three groups: adjacent $(\alpha)$ amino and carboxyl groups and a terminal carboxyl group. At that time they were able to show that the potency of agonists could be altered by changing the chain length separating the adjacent $\alpha$-amino-carboxyl complex from the terminal carboxyl moiety. In this context, the molecular properties of $\mathrm{APB}$ suggested that the $\mathrm{ON}$ bipolar receptor might preferentially interact with an extended form of glutamate, in which the terminal carboxyl group was almost maximally separated from the amino-carboxyl complex. To test this hypothesis, we examined a number of conformationally restricted excitatory amino acid analogues, some of which could match the extended configuration of the glutamate while others could not. Three molecules which serve to epitomize this approach are shown in Figure 7. In the top two molecules shown in Figure 7 , ibotenate and ADCP, the $\mathrm{O}^{-}$on the terminal carboxyl group is shown at a distance of approximately $5 \AA$ from the carbon atom of the $\alpha$-carboxyl group. In contrast, cis-2,3-piperidine dicarboxylic acid (cis-2,3-PDA) in its most extended conformation separates the corresponding carboxyl sites by less than $4 \AA$. Figure 8 illustrates the differential effects of these agents on the $\mathrm{ON}$ bipolar light responses. Ibotenate and ADCP both mimicked the hyperpolarizing action of the photoreceptor transmitter. Furthermore, although they were not as potent as APB, they were selective in that they did not effect horizontal cells or OFF bipolar synaptic responses. In contrast, cis-2,3PDA did not alter the light response of the ON bipolar, although it is described as a general excitatory amino acid antagonist (Davies et al., 1981a), and we have previously demonstrated that cis-2,3-PDA acts at the synaptic receptors of the OFF bipolars and the horizontal cells (Slaughter and Miller, 1983c). Thus, the conformationally extended analogues of glutamate were effective and selective for the $\mathrm{ON}$ bipolar synapse in the outer retina, whereas the folded analogue was comparatively inactive.

In addition to substitutions for the $\omega$ carboxyl group of glutamate, we also tested compounds in which we altered the $\alpha$ 
$1 \mathrm{mM} \mathrm{L-CYSTEINE}$

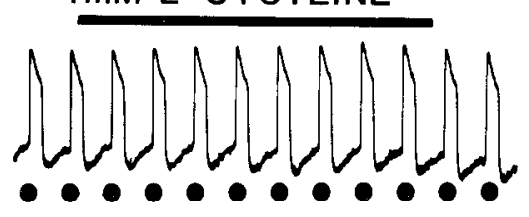

$1 \mathrm{mM}$ L-HOMOCYSTEINE

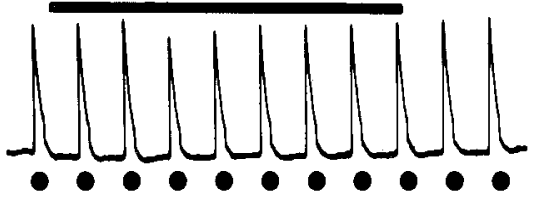

$1 \mathrm{mM} \mathrm{L-CYSTEIC} \mathrm{ACID}$

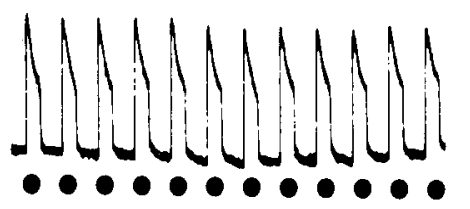

$1 \mathrm{mM} \mathrm{L-HOMOCYSTEIC} \mathrm{ACID}$

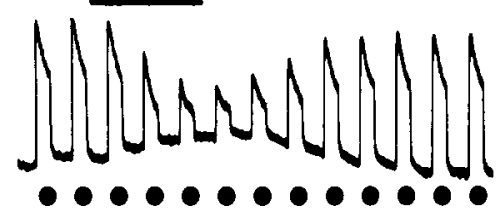

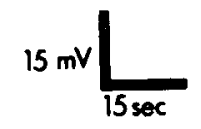

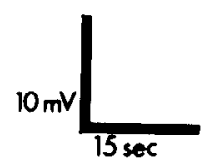

Figure 5. The effects of sulfur-containing amino acid analogues of glutamate and aspartate on the light responses of ON bipolar cells. Only the sulfonic analogue of glutamate was an effective agonist. Circles mark small spot light stimuli.

\section{$1 \mathrm{mM}$ L-SERINE-O-SULPHATE}

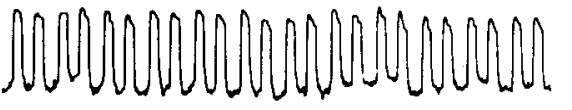

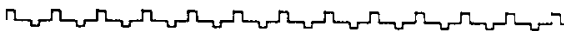

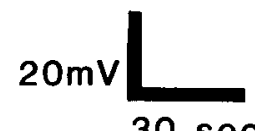

100 UM L-SERINE-O-PHOSPHATE

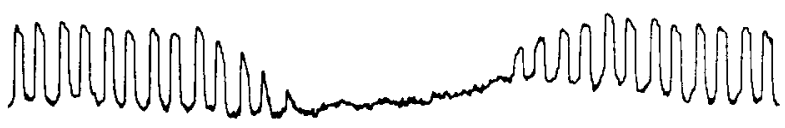

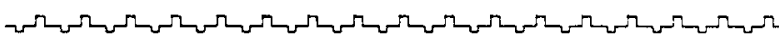

Figure 6. An ON bipolar cell and the contrasts between the effects of two glutamate analogues which contain strongly acidic substitutions in place of the terminal carboxyl group. The upward square pulse represents small spot stimulation, the downward pulse indicates annular stimulation.

carboxyl or amino group. For example, we examined glutamate analogues in which the $\alpha$ carboxyl group was replaced with a phosphonic acid moiety, the hydroxyl group was converted to a methyl or ethyl ester, the $\alpha$ hydrogen was replaced with a methyl group, or a methyl or acetyl group was added to the amino nitrogen. None of these compounds were active at the ON bipolar receptor at concentrations of $1 \mathrm{~mm}$. Therefore, we could not identify the spatial requirements of the $\alpha$ carboxyl $\mathrm{O}^{-}$with regard to the amino group except to confirm previous reports that both groups appear to be required for ligand activity.

Aspartate and glutamate contain adjacent carboxyl and amino groups connected to an $\alpha$ carbon and a terminal carboxyl group at different distances from the $\alpha$ carbon center. In studying the aspartate receptor, McLennan et al. (1982) have tried to determine whether the amino-terminal carboxyl distance or the intercarboxyl distance is more critical for receptor binding. They found that amino glutarate, which has an intercarboxyl distance similar to that of glutamate but an aminocarboxyl distance like that of aspartate, acted like an aspartate analogue. They concluded that for the aspartate receptor the critical distance for ligand binding was the amino-to-terminal carboxyl distance. We have not addressed this question in our analysis of the $\mathrm{ON}$ bipolar glutamate receptor since most of the analogues we tested contained $\alpha$ amino and $\alpha$ carboxyl groups and we considered this end of the molecule as a unit. However, we did test 4-amino-4-phosphonobutyrate, which is a glutamate analogue in which the $\alpha$-carboxylic acid is replaced by a phosphate group. This moves the $\mathrm{O}^{-}$corresponding to that of the $\alpha$ carboxyl further from the amino- and the terminal carboxylbinding sites. At $1 \mathrm{mM}$, this compound was ineffective at the ON bipolar synapse. This suggests that the positioning of the $\alpha$ carboxyl group is critical to binding for the extenderl glutamate receptor.

With these results we modeled the ligand that could activate the ON bipolar receptor by comparing the molecular conformations of APB, ibotenate, L-o-phosphoserine, and ADCP. All of these compounds had identically spaced $\alpha$ amino and carboxyl groups so that, in essence, this modeling identified the location of the terminal $\mathrm{O}^{-}$in relation to these other binding sites. The results of this comparison are shown schematically in Figure 9. This spacing of the three binding sites matches the extended conformation of glutamate. We have tested several other compounds and correlated their activity with their ability to match the molecular constraints of the model. All of the agents that were potent agonists at the $\mathrm{ON}$ bipolar receptor, such as kainic acid, AMPA, quisqualate, and homocysteic acid, were able to match this extended configuration. On the other hand, several conformationally constrained excitatory amino acid analogues that were ineffective, such as cis-2,3-PDA, trans2,3-PDA, and trans-2,5-PDA, could not assume the configura- 

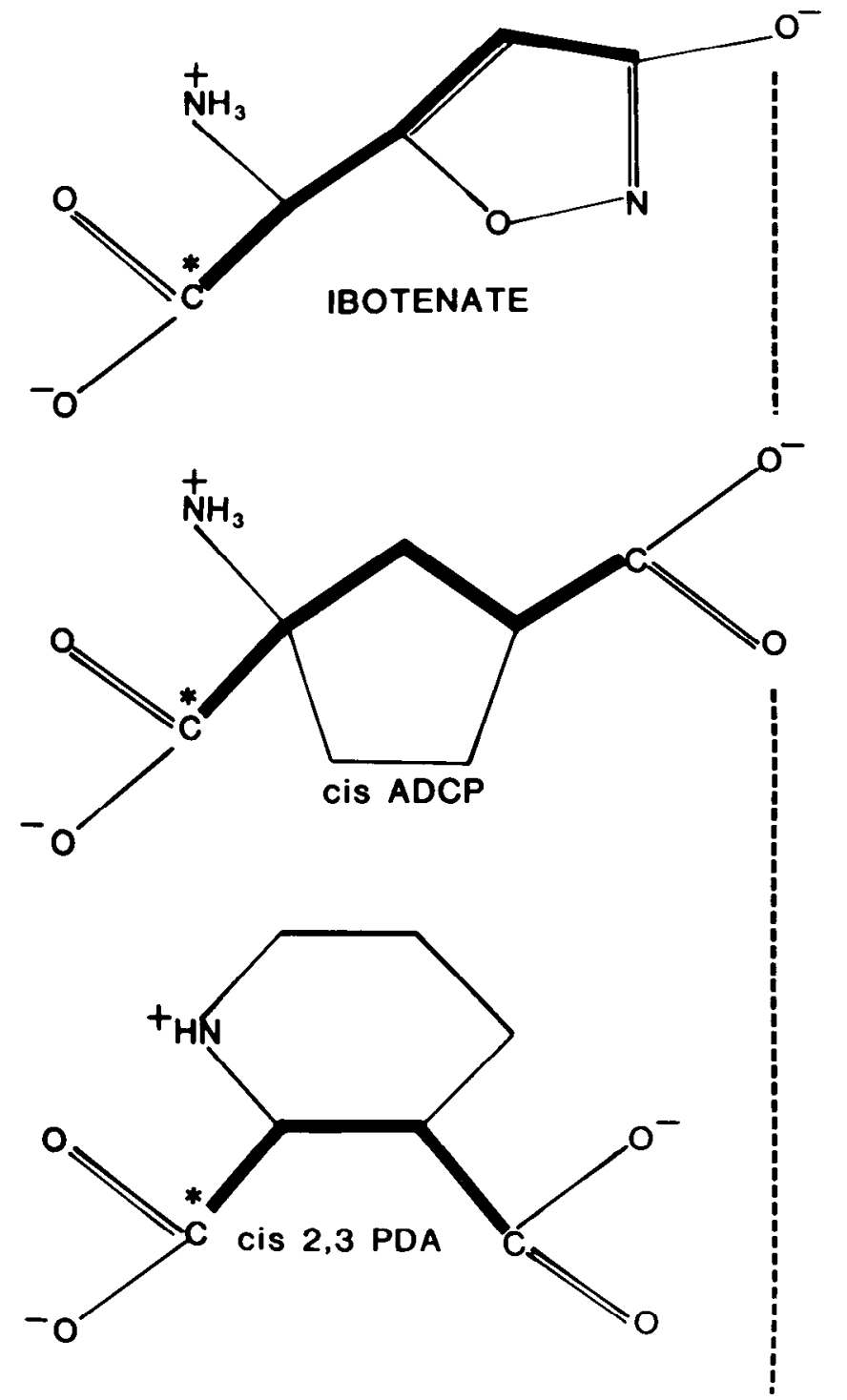

Figure 7. Schematic depiction of the conformational differences between three acidic amino acid analogues. The dashed line marks a distance of approximately $5 \hat{A}$ from the terminal oxygen to the $\alpha$ carbon $(\stackrel{*}{C})$. cis-1,3-Amino dicarboxycyclopentane (cis $A D C P$ ) and ibotenate can match this extended conformation, whereas cis-2,3-piperidine dicarboxylic acid (cis 2,3 PDA) cannot.

tion of the model ligand. All of these compounds have been shown to interact with excitatory amino acid receptors at other sites so that their ineffectiveness was not simply a reflection of patent inactivity. trans-2,5-PDA is particularly interesting because it can assume an extended conformation but not one that matches the three-dimensional constraints of the ligand model.

\section{Discussion}

Emerging from the observations of Murakami et al. (1972, 1975), excitatory amino acids have been shown to mimic the action of the photoreceptor transmitter in amphibians (Marshall and Werblin, 1978; Slaughter and Miller, 1981, 1983a, c), reptiles (Cervetto and MacNichol, 1972), and mammals (Bloomfield and Dowling, 1982; Massey and Miller, 1983), as well as other studies in fish (Wu and Dowling, 1978; Lasater and Dowling, 1982; Rowe and Ruddock, 1982). Uptake of radiolabeled amino acids (Marc and Lam, 1981) and aspartate aminotransferase immunohistochemistry (Altschuler et al., 1982; Lin et al., 1983) and the combination of these two techniques (Brandon and Lam, 1983) also suggest that photoreceptors use a dicarboxylic amino acid neurotransmitter. Further support comes from experiments to detect release of labeled, preloaded amino acids (Bauer et al., 1981; Miller and Schwartz, 1983) or endogenous amino acids (Miller et al., 1982) from photoreceptors and from the excitatory amino acid-stimulated release of GABA from horizontal cells (Schwartz, 1982; Yazulla, 1983). However, a pharmacological analysis has been thwarted until recently by the lack of effective excitatory amino acid antagonists. Exceptions have been the characterization of an aspartate-like receptor on one type of fish horizontal cell using the antagonist $\alpha$-aminoadipate (Wu and Dowling, 1978) and the demonstration that cis-2,3-PDA, acting as a glutamate antagonist, blocks the light responses of OFF bipolar and horizontal cells in the mudpuppy retina (Slaughter and Miller, $1983 \mathrm{c})$. Because of this general lack of antagonists, conformationally restricted and presumably selective agonists have been developed and used in an effort to differentiate and characterize excitatory amino acid receptors in the vertebrate nervous system (Watkins and Evans, 1981; McLennan, 1981). This approach led to the identification of several types of glutamate and aspartate receplors. Unfortunately, because these agonists generally act by opening ionic channels, it is difficult to distinguish between synaptic and nonsynaptic sites of action for these agents. In the $\mathrm{ON}$ bipolar cells, because excitatory amino acids and the endogenous transmitter both close ionic channels, one can show that the agonists act synaptically. This has permitted the use of a plethora of excitatory amino acid agonists to characterize this synaptic receptor.

A principal aim of our experiments was to determine whether the ON bipolar receptor preferred glutamate-like or aspartatelike ligands. With a variety of compounds used to investigate this distinction, the results consistently indicated that glutamate analogues were more effective. The phosphonic analogue of glutamate (APB) was more potent than the corresponding aspartate analogue (2-amino-3-phosphonopropionate). Homocysteic acid, the sulfonic acid analogue of glutamate, was also more potent than cysteic acid, the aspartate analogue. A group of glutamate analogues, which included kainic acid, quisqualic acid, and AMPA, was characterized as potent agonists, whereas $N$-methyl aspartate, $\alpha$-aminoadipate, $\alpha$-aminosuberate, and $\alpha$ methylglutamate, which are considered to act at aspartatc receptors, were all ineffective at the ON bipolar synapse. Further support for glutamate as a photoreceptor transmitter in the mudpuppy has come from a preliminary high pressure liquid chromatography analysis of the light-modulated release of endogenous amino acids from retinas in which all post-photoreceptor light activity had been suppressed by pharmacological agents. An analysis of the amino acids released in the dark after a period of light stimulation showed that glutamate but not aspartate increased, and this release was calcium dependent (Miller et al., 1982). Since photoreceptors release transmitter maximally in the dark, this points to glutamate as a photoreceptor neurotransmitter.

We have recently shown that not only the ON bipolar, but also the OFF bipolar and horizontal cells in mudpuppy have synaptic glutamate-like receptors (Slaughter and Miller, $1983 \mathrm{c}$ ), as do amacrine and ganglion cells (Slaughter and Miller, $1983 \mathrm{~b})$. Thus, our original report that APB acted only at the ON bipolar receptor indicates that this is a unique type of glutamate receptor. This APB receptor is apparently associated with $O N$ bipolar neurons in a variety of vertebrate retinas including the dogfish (Shiells et al., 1981), rabbit (Neal et al., 1981; Bloomfield and Dowling, 1983), cat (Horton and Sherk, 1984), and monkey (Schiller, 1982). In the literature, the present classification of excitatory amino acid receptors suggests there are three types: (1) a quisqualate-sensitive glutamate receptor, (2) an $N$-methyl aspartate-sensitive aspartate recep- 


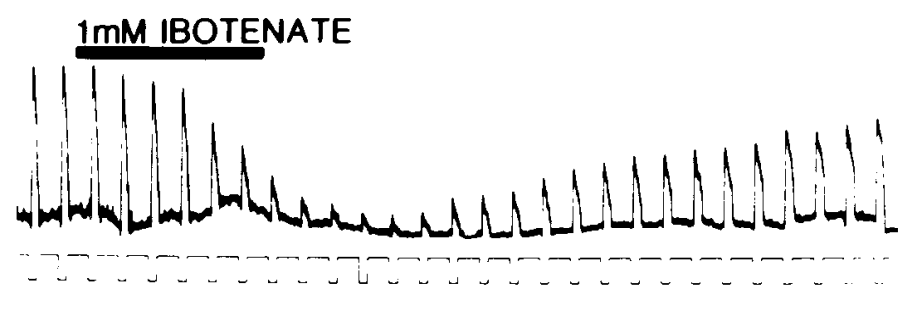

Figure 8 . The effects on $\mathrm{ON}$ bipolar cells of the agents illustrated in Figure 7. The conformationally extended analogues were effective agonists. The light stimulus was a diffuse light in the top trace, and alternating small spot and annular stimuli in the two lower traces.

\section{$1 \mathrm{mM}$ cis ADCP}

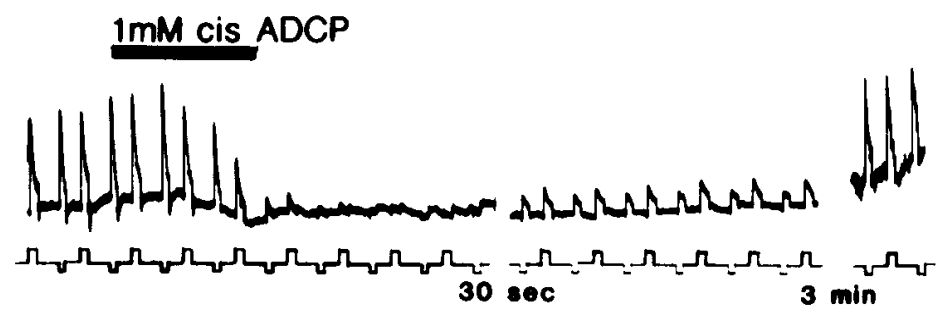

$6 \mathrm{mM}$ cis2,3 PDA

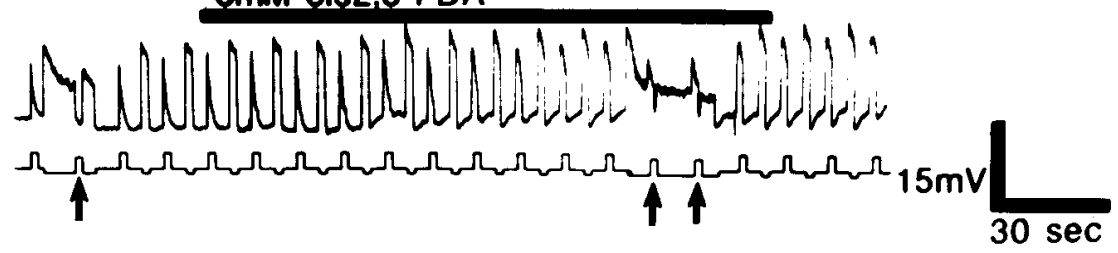

tor, and (3) a kainate-sensitive, possible second type of glutamate receptor (Watkins and Evans, 1981; McLennan, 1981). Our data in the outer retina of the mudpuppy indicate that all three classes of second-order neurons are sensitive to kainate and quisqualate (both agents are of similar potency) but insensitive to $N$-methyl aspartate (Slaughter and Miller, 1983a). But none of these conventional, selective agonists help to distinguish the APB receptor. The present analysis suggests that APB manifests an extended glutamate receptor in which the intercarboxyl distance is approximately $4 \mathrm{~A}$. The $\mathrm{O}^{-}$of the terminal carboxyl group can be localized in space with relation to the other two binding sites. This is based on a correlation of the molecular configurations of ibotenate, ADCP, and APB. This comparison produced only one location for this terminal $\mathrm{O}^{-}$which all three molecules have in common. This model is also consistent with the effectiveness of the other analogues we have tested. That is, agents that act at the ON bipolar receptor, such as L-serine-o-phosphate, 2-amino-5-phosphonovalerate, AMPA, kainate, and quisqualate can all match the spatial constraints of the model. Several agents that cannot fit this model, such as cis-2,3-PDA, trans-2,3-PDA, trans-2,5-PDA, and $\mathrm{D}$ - $\alpha$-aminoadipate, are ineffective at this receptor although they are active at other excitatory amino acid receptor sites. This model rests, to some extent, on the supposition that each synaptic receptor has one glutamale-binding site (or multiple, identical sites). This is supported by binding studies cited below suggesting a Hill coefficient near unity.

Relating this model of the extended glutamate receptor to the molecular structure of APB suggests why APB is a potent agonist at the $\mathrm{ON}$ bipolar synapse. The size of the phosphate moiety favors an extended conformation of this ligand and both of the terminal, phosphate $\mathrm{O}^{-} \mathrm{s}$ can match the proposed binding site of the receptor when APB is in the extended configuration. This combination apparently contributes to the efficacy of APB and indicates that it can be a useful pharmacological agent for the identification of this class of glutamate receptor.

This extended glutamate receptor is not unique to the retina. The studies of White et al. (1979) and Koerner and Cotman (1981) demonstrated the presence of an APB-sensitive receptor in the perforant pathway in the hippocampus. Binding studies in the hippocampus have disclosed a distinct group of APBbinding sites with a $K_{\mathrm{D}}$ of $5 \mu \mathrm{M}$, a $B_{\max }$ of $85 \mathrm{pmol} / \mathrm{mg}$ of protein, and a Hill coefficient of approximately 1 . Binding studies in retina (Mitchell and Redburn, 1981) and rat brain (Butcher et al., 1983) revealed a similar class of receptors. The $\mathrm{IC}_{50}$ of several glutamate analogues such as AMPA, ibotenate, serine-o-phosphate, and cis-2,3-PDA, indicates that the receptor analyzed in these binding studies is pharmacologically similar to the ON bipolar receptor in the retina. Furthermorc, Mena et al. (1982) and Fagg et al. (1982) have shown that APB binding to this receptor is chloride dependent. They have suggested that the APB-sensitive glutamate receptor is coupled to a chloride ionophore. This correlates with studies of the ionic mechanism of the ON bipolar cells in mudpuppy (Miller and Dacheux, 1976).

In assessing the excitatory amino acid pharmacology of the ON bipolar receptor we used two agents, ADCP (Hall et al., 1979) and 2-amino-5-phosphonovalerate (Davies et al., 1981b), which have been described as $N$-methyl aspartate receptor selective. These two agents do appear to act at $N$-methyl aspartate receptor sites which are present in the proximal retina. However, in the distal retina of the mudpuppy, $N$ methyl aspartate receptors do not appear to modulate neurotransmission from photoreceptor cones to second-order neurons (Slaughter and Miller, 1983a), and yet these compounds are active at the $\mathrm{ON}$ bipolar synapse. Both agents can assume the extended conformation proposed for the extended glutamate receptor which can account for their activity. Presumably, these compounds interact with the $N$-methyl aspartate receptor when in a slightly more folded conformation. ADCP and 2amino-5-phosphonovalerate are more potent at the $N$-methyl aspartate receptor, but their action at the $A P B$ receptor suggests a limitation in their usefulness in identifying aspartate receptors.

Each class of second-order neuron in the mudpuppy retina contains a distinct type of glutamate-like receptor (Slaughter et al., 1983). The present convention of dividing glutamate receptors into two classes, quisqualate and kainte preferring, 


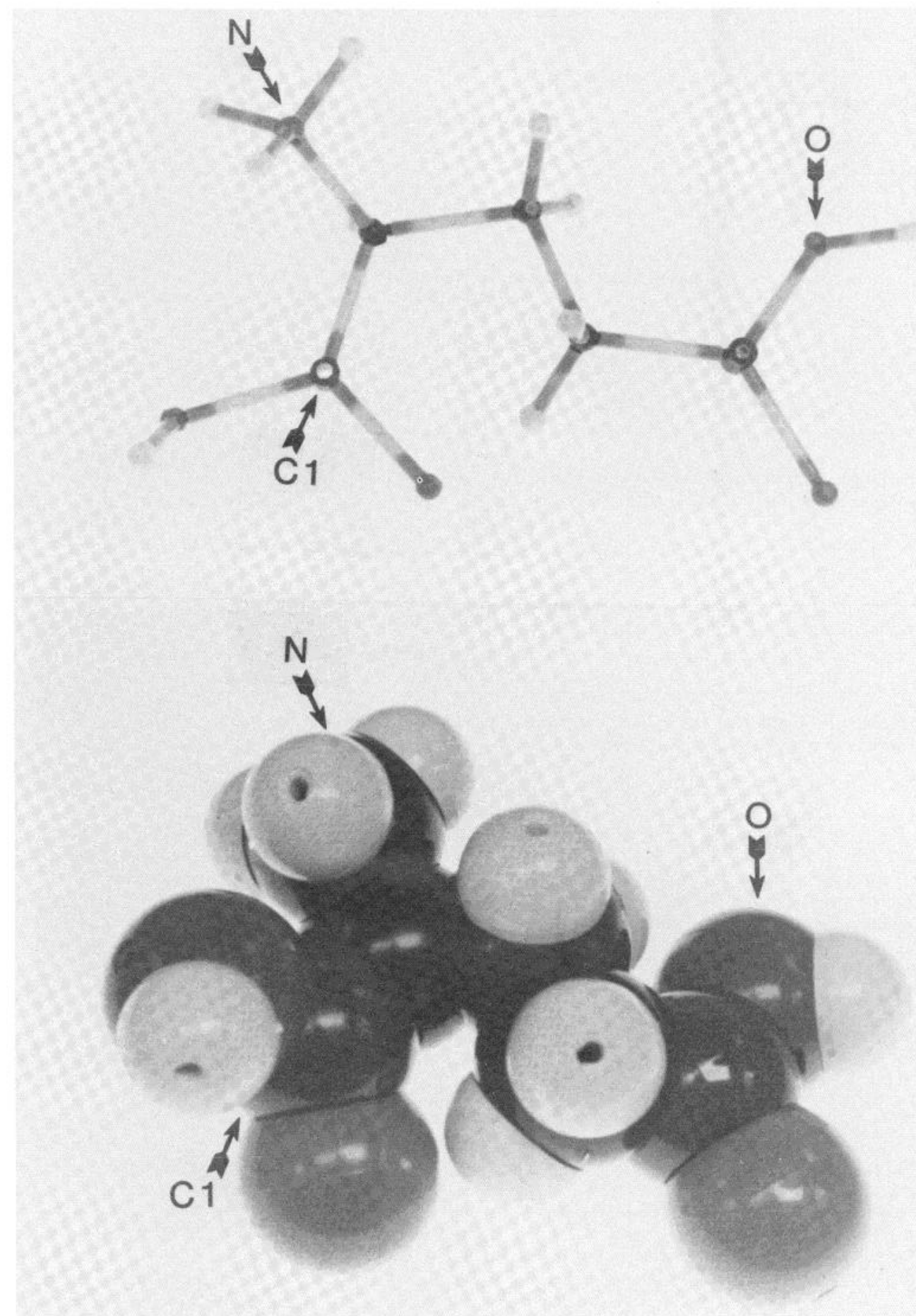

Figure 9. Molecular models of glutamate which match the common conformational properties of all of the analogues which were effective agonists at the $\mathrm{ON}$ bipolar synaptic receptor. This model corresponds to an extended conformation of glutamate in which the $\alpha$ and terminal carbon atoms are approximately $4 \AA$ apart and the terminal oxygen is approximately $5 \AA$ from the $\alpha$ carbon.

does not adequately describe these receptors. Although our analysis of the OFF bipolar and horizontal cell receptors is more preliminary, our results raise the possibility that these three types of glutamate receptors can be characterized on the basis of the glutamate conformation that preferentially binds and activates the receptor. In this scheme, the ON bipolar receptor selectively binds to glutatmate in its extended conformation, whereas the OFF bipolars and the horizontal cells preferentially interact with glutamate when it is in a folded or a partially folded conformation, respectively (Slaughter et al.,
1983). This is similar to the explanation of multiple receptor types for other neurotransmitters such as acetylcholine (Martin-Smith et al., 1967) and histamine (Kier, 1968: Ganellin, 1973, 1982).

\section{References}

Altschuler, R. A., J. L. Mosinger, G. C. Harmison, M. H. Parakkal, and R. J. Wenthold (1982) Aspartate aminotransferase-like immunoreactivity as a marker for aspartate/glutamate in guinea pig photoreceptors. Nature 298: 657-659. 
Ariel, M., S. C. Mangel, and J. E. Dowling (1982) Effects of amino acid antagonists on spectral properties of fish horizontal cells. Invest. Ophthalmol. Vis. Sci. Suppl. 22: 81 .

Bauer, B., B. Ehinger, and K. Tornqvist (1981) Release of some neurotransmitters from the retina. Vision Res. 21: 1665-1672.

Bloomfield, S. A., and J. E. Dowling (1982) The actions of aspartate and glutamate and their analogs on retinal neurons of the rabbit. Soc. Neurosci. Abstr. 8: 131.

Bloomfield, S. A., and J. E. Dowling (1981) The actions of 2-amino-4phosphonobutyric acid on retinal neurons of the rabbit. Invest. Ophthalmol. Vis. Sci. Suppl. 24: 221.

Brandon, C., and D. M. -K. Lam (1983) L-Glutamic acid: A neurotransmitter candidate for cone photoreceptors in human and rat retinas. Proc. Natl. Acad. Sci. U. S. A. 80: 5117-5121.

Butcher, S. P., J. F. Collins, and P. J. Roberts (1983) Characterization of the binding of DL- $\left[{ }^{3} \mathrm{H}\right]$-2-amino-4-phosphonobutyrate to L-glutamate-sensitive sites on rat brain synaptic membranes. Br. J. Pharmacol. 80: 355-364.

Cervetto, L., and E. F. MacNichol, Jr. (1972) Inactivation of horizontal cells in the turtle retina by glutamate and aspartate. Science 178: 767-768.

Curtis, D. R., and J. C. Watkins (1960) Excitation and depression of spinal cord neurones by structurally related amino acids. J. Neurochem. 6: 117-141.

Dacheux, R. F., and R. F. Miller (1976) Photoreceptor bipolar cell transmission in the perfused retina eyecut of the mudpuppy. Science 191: $963-964$.

Davies, J., R. H. Evans, A. A. Francis, A. W. Jones, and J. C. Watkins (1981a) Antagonism of excitatory amino acid-induced and synaptic excitation of spinal neurones by cis-2,3-piperidine dicarboxylate. J. Neurochem. 36: 1305-1307.

Davies, J., A. A. Francis, A. W. Jones, and J. C. Watkins (1981b) 2Amino-5-phosphonovalerate (2APV), a potent and selective antagonist of amino acid-induced and synaptic excitation. Neurosci. Lett. 21: 77-81.

Dowling, J. E., and F. Werblin (1969) Organization of retina of the mudpuppy, Necturus maculosus. I. Synaptic structure. J. Neurophysiol. 32: 315-338.

Fagg, G. E., A. C. Foster, E. E. Mena, and C. W. Cotman (1982) Chloride and calcium ions reveal a pharmacologically distinct population of L-glutamate binding sites in synaptic membranes: Correspondence between biochemical and electrophysiological data. J. Neurosci. 2: 958-965.

Ganellin, C. R. (1973) Conformation of histamine derivatives. III. A relationship between conformation and pharmacological activity. J. Med. Chem. 16: 620-623.

Ganellin, C. R. (1982) Chemistry and structure-activity relationships of drugs acting at histamine receptors. In Pharmacology of Histamine Receptors, C. R. Ganellin and M. E. Parsons, eds., pp. 10-102, Wright PSG, Bristol, England.

Hall, J. G., T. P. Hicks, H. McLennan, T. L. Richardson, and H. V. Wheal (1979) The excitation of mammalian central neurones by amino acids. J. Physiol. (Lond.) 286: 29-39.

Horton, J. C., and H. Sherk (1984) Receptive field properties in the cat's lateral geniculate nucleus in the absence of ON-center retinal input. J. Neurosci. 4: 374-380.

Kaneko, A. (1970) Physiological-morphological identification of horizontal, bipolar, and amacrine cells in goldfish retina. J. Physiol. (Lond.) 207: 622-633.

Kaneko, A., and H. Shimazaki (1975) Synaptic transmission from photoreceptors to horizontal cells in the carp retina. Cold Spring Harbor Symp. Quant. Biol. 40: 537-546.

Kehoe, J. S. (1967) Pharmacological characteristics and ionic basis of a two component postsynaptic inhibition. Nature 215: 1503-1505.

Kehoe, J. S. (1969) Single presynaptic neurone mediates a two component postsynaptic inhibition. Nature 221:866-868.

Kier, L. B. (1968) Molecular orbital calculations of the preferred conformations of histamine and a theory on its dual activity. J. Med. Chem. 11: 441-445.

Koerner, J. F., and C. W. Cotman (1981) Micromolar L-2-amino-4phosphonobutyric acid selectively inhibits perforant path synapses from lateral entorhinal cortex. Brain Res. 216: 192-198.

Lasater, E. M., and J. E. Dowling (1982) Carp horizontal cells in culture respond selectively to L-glutamate and its agonists. Proc. Natl. Acad. Sci. U. S. A. 79: 936-940.
Libet, B. (1979) Which postsynaptic action of dopamine is mediated by cyclic AMP. Life Sci. 24: 1043-1058.

Lin, C. -T., H. -Z. Li, and J. -Y. Wu (1983) Immunocytochemical localization of L-glutamate decarboxylase, gamma-aminobutyric acid transaminase, cysteine sulfinic acid decarboxylase, aspartate aminotransferase and somatostatin in rat retina. Brain Res. 270: 273283.

Marc, R. E., and D. M. -K. Lam (1981) Uptake of aspartic and glutamatic acid by photoreceptors in goldfish retina. Proc. Natl. Acad. Sci. U. S. A. 78: 7185-7189.

Marshall, L. M., and F. S. Werblin (1978) The synaptic transmission to the horizontal cells in the retina of the larval tiger salamander. J. Physiol. (Lond.) 279: 321-346.

Martin-Smith, M., G. A. Smail, and J. B. Stenlake (1967) The possible role of conformational isomerism in the biological actions of acetylcholine. J. Pharm. Pharmacol. 19: 561-589.

Massey, S. C., and R. F. Miller (1983) Amino acid analogues on horizontal cell responses in rabbit retinal. Invest. Ophthalmol. Vis. Sci. Suppl. 24: 222.

McLennan, H. (1981) On the nature of the receptors for various excitatory amino acids in the mammalian central nervous system. In Glutamate as a Neurotransmitter, G. DiChiara and G. L. Gessa, eds., pp. 253-262, Raven Pres, New York.

McLennan, H., T. P. Hicks, and J. R. Liu (1982) On the configuration of the receptors for excitatory amino acids. Neuropharmacology 21 : $549-554$.

Mena, E. E., G. E. Fagg, and C. W. Cotman (1982) Chloride ions enhance L-glutamate binding to rat brain synaptic membranes. Brain Res. 243: 378-381.

Miller, A., and E. A. Schwartz (1983) Evidence for the identification of synaptic transmitters released by photoreceptors of the toad retina. J. Physiol. (Lond.) 334: 325-350.

Miller, R. F., and R. F. Dacheux (1976) Synaptic organization and ionic basis of $\mathrm{ON}$ and $\mathrm{OFF}$ channels in the mudpuppy retina. I. Intracellular analysis of chloride-sensitive electrogenic properties of receptors, horizontal cells, bipolar cells and amacrine cells. J. Gen. Physiol. 67: 639-659.

Miller, R. F., M. M. Slaughter, and S. C. Massey (1982) Light- and dark-dependent release of glutamate and aspartate in the isolated retina of the mudpuppy. Soc. Neurosci. Abstr. 8: 131.

Mitchell, C. K., and D. A. Redburn (1982) 2-Amino-4-phosphonobutyric acid and $N$-methyl-D-aspartate differentiate between $\left[{ }^{3} \mathrm{H}\right]$ glutamate and $\left[{ }^{3} \mathrm{H}\right]$ aspartate binding in bovine retina. Neurosci. Lett. 28: $241-246$

Murakami, M., K. Ohtsu, and T. Ohtsuka (1972) Effects of chemicals on receptors and horizontal cells in the retina. J. Physiol. (Lond.) 227: 889-913.

Murakami, M., T. Ohtsuka, and H. Shimazaki (1975) Effects of aspartate and glutamate on the bipolar cells in the carp retina. Vision Res. 15: $456-458$

Neal, M. J., J. R. Cunningham, T. A. James, M. Joseph, and J. F. Collins (1981) The effect of 2-amino-4-phosphonobutyric acid (APB) on acetylcholine release from the rabbit retina: Evidence for onchannel input to cholinergic amacrine cells. Neurosci. Lett. 26: 301305 .

Nelson, R. (1973) A comparison of electrical properties of neurons in Necturus retina. J. Neurophysiol. 36: 519-535.

Rowe, J. S., and K. H. Ruddock (1982) Depolarization of retinal horizontal cells by excitatory amino acid neurotransmitter agonists. Neurosci. Lett. 30: 257-262.

Schiller, P. H. (1982) Central connections of the retinal ON and OFF pathways. Nature 297: 580-583.

Schwartz, E. A. (1982) Calcium-independent release of G $\Lambda \mathrm{B} \Lambda$ from isolated horizontal cells of the toad retina. J. Physiol. (Lond.) 323: 211-227.

Shiells, R. A., G. Falk, and S. Naghshinen (1981) Action of glutamate and aspartate analogues on rod horizontal and biolar cells. Nature 294: 592-594.

Slaughter, M. M., and K. F. Miller (1981) 2-Amino-4-phosphonobutyric acid: A new pharmacological tool for retina research. Science 211: $182-185$.

Slaughter, M. M., and R. F. Miller (1983a) The role of excitatory amino acid transmitters in the mudpuppy retina: An analysis with kainic acid and $N$-methyl aspartate. J. Neurosci. 3: 1701-1711.

Slaughter, M. M., and R. F. Miller (1983b) Bipolar cells in the mud- 
puppy retina use an excitatory amino acid neurotransmitter. Nature 303: $537-538$.

Slaughter, M. M., and R. F. Miller (1983c) An excitatory amino acid antagonist blocks cone input to sign-conserving second-order retinal neurons. Science 219: 1230-1232.

Slaughter, M. M., B. Kalman, and R. F. Miller (1983) Modelling of glutamate receptors in the distal retina of the mudpuppy. Soc. Ncurosci. Abstr. 9: 736.

Toyoda, J. (1973) Membrane resistance changes underlying the bipolar cell response in the carp retina. Vision Res. 13: 283-294.

Watkins, J. C., and R. H. Evans (1981) Excitatory amino acid transmitters. Annu. Rev. Pharmacol. Toxicol. 21: 165-204.

Werblin, F., and J. E. Dowling (1969) Organization of retina of the mudpuppy, Necturus maculosus. II. Intracellular recording. J. Neurophysiol. 32: 339-355.
Werblin, F. S. (1979) Integrative pathways in local circuits between slow-potential cells in the retina. In The Neurosciences: Fourth Study Program, F. O. Schmitt and F. G. Worden, eds., pp. 193-212, MIT Press, Cambridge, MA.

White, W. F., J. V. Nadler, and C. W. Cotman (1979) The effect of acidic amino acid antagonists on synaptic transmission in the hippocampal formation in vitro. Brain Res. 164: 177-194.

Wu, S. M., and J. E. Dowling (1978) L-Aspartate: Evidence for a role in cone photoreceptor synaptic transmission in the carp retina. Proc. Natl. Acad. Sci. U. S. A. 75: 5205-5209.

Yazulla, S. (1983) Stimulation of GABA release from retinal horizontal cells by potassium and acidic amino acid agonists. Brain Res. 275: 61-74. 